\title{
Gramáticas de la convivencia. Estudio sobre la convivencia en La Salut y Sant Joan de Llefià, Badalona
}

\author{
Victoria Sánchez Antelo* \\ Mònica Plana" \\ Fátima Taleb, Isidre Ferreté, Hassan Hammich, Muniba Munir ${ }^{* *}$ \\ Josep Palau, Antonio de la Rosa, Pilar Laporta \\ y Mònica Tolsanas*
}

\begin{abstract}
Resumen: Los procesos migratorios suponen repensar las relaciones, tránsitos y vivencias de las comunidades receptoras. En este sentido, el análisis de los escenarios de convivencia urbana implica redescubrir las historias viejas y nuevas de la inmigración, de la construcción del barrio, de la conformación de sus actores colectivos y de los espacios urbanos comunes. En el análisis de los escenarios de convivencia más conflictivos, encontramos giros discursivos que buscan responsabilizar a la inmigración reciente de problemáticas estructurales que se viven como irremediables. Otros discursos, tendientes a la indiferencia respecto a la convivencia, muestran un potencial conflicto que vuelve inestables estas posturas. El escenario de convivencia social parece construirse desde acciones que buscan la implicación e interrelación entre los actores, desde el conocimiento y reconocimiento de las diferencias y con acento en los derechos comunes.

Palabras clave: convivencia, inmigración, ciudadanía
\end{abstract}

\section{Grammars of communal life}

Abstract: The migratory processes involve rethinking the relations, transits and experiences of the host communities. In this regard, the analysis of urban communal life's scenarios implies rediscovering the old and new stories of immigration, construction of neighbourhood, conformation of their collective actors and urban common spaces. In the analysis of the most contentious coexistence scenarios, we found discursive changes, that intent to blame the newcomer immigrant for structural problems that are being experienced as irremediable. Other speeches, that tend towards indifference in regards to communal life, show a potential conflict that make these positions unstable. The social communal life scenario seems to

\footnotetext{
*Associació Benestar i Desenvolupament, Barcelona, España. Email: vsanchez@abd-ong.org ***Associació Benestar i Desenvolupament, Barcelona, España. Email: mplana@ abd-ong.org

*** Comisión de Convivencia del PLADECO de La Salut y Sant Joan de Llefià, compuesta por vecinos y vecinas del barrio de origen marroquí, pakistaní y catalán.

***** Técnicos del Ayuntamiento de Badalona, docente del IES Barres i Ones; TS del Ambulatorio Llefià
} 
be built from actions that search for implication and interrelation between actors, starting out from the knowledge and appreciation of differences and highlighting the common rights.

Keywords: communal life, immigration, citizenship

\section{Introducción}

El presente documento es una síntesis del estudio "Gramáticas de la convivencia" realizado por la Comisión de Convivencia del PLADECO de La Salut y Sant Joan de Llefià, de Badalona, Catalunya, conjuntamente con la Associació Benestar i Desenvolupament (ABD). Dicho estudio ha tenido como finalidad indagar acerca de los procesos de inserción social de la población inmigrante reciente con especial atención a su incidencia en la convivencia entre vecinos y vecinas (nuevos y viejos) de dos barrios del área metropolitana de Barcelona: La Salut y St. Joan de Llefià del municipio de Badalona. En los últimos años, dichos barrios fueron escenario de diversas batallas discursivas, con fuertes consecuencias sobre las relaciones entre sus vecinos.

En primer lugar, la inmigración como "tema", y los escenarios de convivencia que plantea su presencia, han sido centro de enfrentamiento de los principales representantes políticos ${ }^{1} \mathrm{y}$ ha teñido en gran parte los discursos de los vecinos y vecinas, sea por adhesión o por oposición. En segundo lugar, en uno de estos barrios, se realizaron una serie de manifestaciones, lideradas por habitantes y asociaciones del barrio, demandando la expulsión de una familia de inmigrantes. ${ }^{2}$ En tercer lugar, numerosos periódicos anunciaban tiempo atrás operativos policiales para desarticular una red presuntamente vinculada al terrorismo internacional, en las cuales estarían implicados vecinos del barrio. ${ }^{3}$

Este escenario ha generado un fuerte sentimiento de desconfianza, violencia y malestar, profundizando la fragmentación social preexistente. El estudio pretende por tanto identificar aquellos procesos, espacios y actores sociales que promueven el acercamiento y contrarresten los mensajes de terror y desconfianza de los medios de comunicación, líderes políticos y políticas carentes de contenido. Estos episodios no sólo marcaron las opiniones de los vecinos, sino que resaltaron la necesidad de definir

\footnotetext{
${ }^{1}$ Elecciones municipales del 27 de mayo de 2007 cuya campaña política se desarrollo desde comienzos de año, pero con mayor intensidad durante abril y mayo.

${ }^{2}$ Cf. La Vanguardia del 04 de febrero de 2007. También publicado en otros periódicos de difusión masiva en España en la misma fecha.

${ }^{3}$ Cf. La Vanguardia del 29 de mayo de 2007. También publicado en otros periódicos de difusión masiva en España en la misma fecha.
} 
estrategias de resolución de conflictos, analizar el papel de las entidades e instituciones en el proceso de integración/exclusión de los nuevos vecinos (inmigrantes), el papel de la administración local en la gestión de las relaciones sociales y en la promoción de la cohesión social en el nuevo contexto. En este sentido, se ha buscado interpelar a las voces de quienes viven, trabajan y transitan los barrios, para conocer qué sienten, cómo viven y qué convivencia desean construir en el nuevo escenario multicultural.

\section{Contexto actual}

En los últimos seis años, Catalunya ha experimentado un aumento considerable de población inmigrante. Esta, de una gran heterogeneidad en cuanto a su procedencia, se concentra mayoritariamente en el área metropolitana y en la franja litoral. El fenómeno ha generado grandes transformaciones tanto para la sociedad como para quienes arriban a ella. En el ámbito local, la presencia de personas provenientes de distintos países redefine las relaciones entre los distintos actores sociales. Para las instituciones de la administración, la gestión de las nuevas dinámicas sociales se convierte en un desafío. Cada espacio público, cada servicio, requerirá una nueva forma de abordaje y una gestión de las relaciones entre autóctonos e inmigrantes. En este sentido, las características poblacionales de los barrios, los tiempos y volúmenes de nueva población que se incorpora en los últimos años, así como su distribución territorial, son algunos datos que nos definen el contexto global en el que se desarrollan los distintos escenarios de convivencia que analizaremos.

\section{Antigüedad y volumen del fenómeno}

Un precepto que se repite constantemente sobre los procesos de inmigración reciente refiere a la rapidez y el volumen de población con que se han producido. Esto ha implicado para la población autóctona un proceso de cambio muy acelerado en su entorno. En el municipio de Badalona, se produce un incremento anual promedio de 57 puntos de población proveniente de países en vías de desarrollo. Mientras que en el año 2000 los registros en Badalona alcanzan a las 1.121 personas nacidas de fuera del territorio español, en el 2006 estas ascienden 5.912. En líneas generales, se observa a partir del año 2000 que el número de personas provenientes de otros países registradas anualmente en el territorio crece a un ritmo sostenido, llegando a su punto máximo en el año 2003.

\section{Concentración espacial}

Si centramos la atención en la distribución territorial de la población proveniente de otros países, en el municipio de Badalona se observa que en la zona de Serra d'en Mena junto con los barrios de Sant Roc, Artigas y El Remei se concentra la mayor proporción de población inmigrante. 
Sobre datos del 2006, se observa que, después de Sant Roc y La Pau, la proporción de inmigrantes registrada sobre el total de población en La Salut es de las más altas del municipio (31\%). En el caso de Sant Joan de Llefià, la proporción es bastante menor: 16\%. Las características de la inserción urbana de esta población suponen un gran desafío para la gestión de las relaciones y los conflictos.

\section{Gráfico $\mathbf{N}^{0} 1$.}

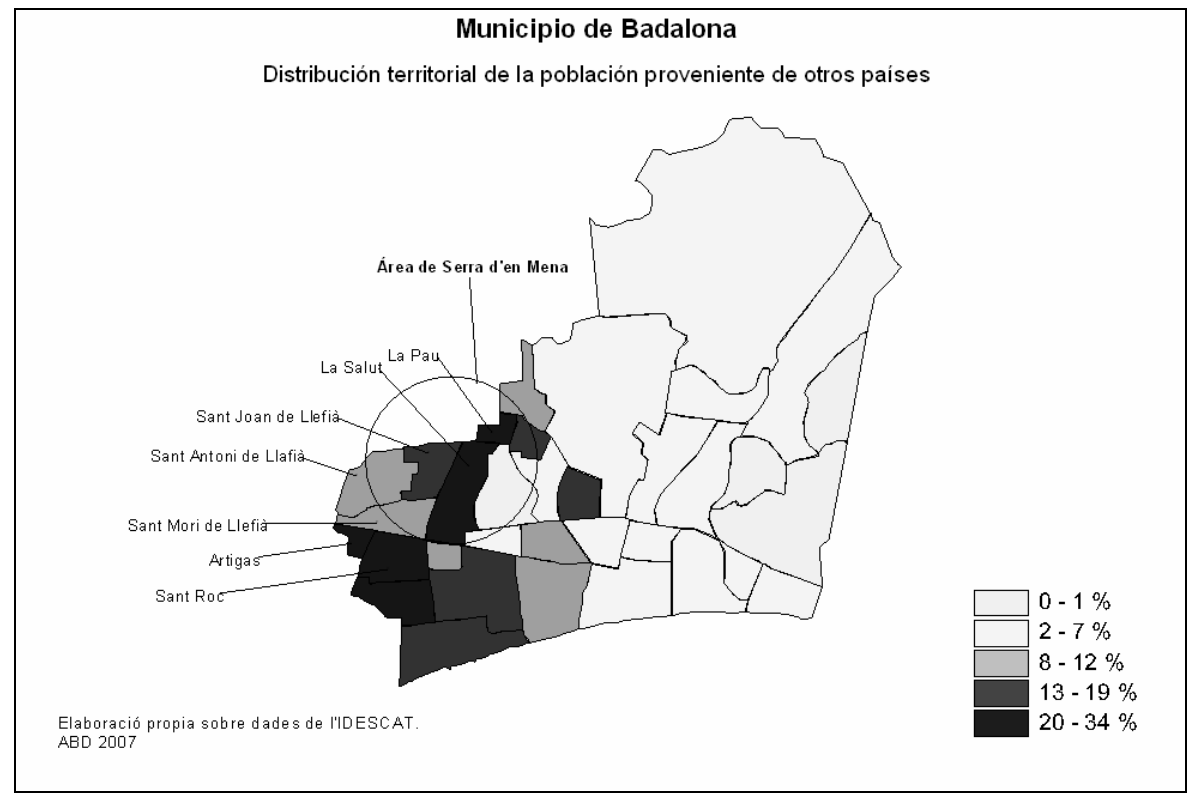

\section{Procedencia}

Si se distingue la población inmigrante según la región del mundo, observamos que las personas provenientes de Asia -esencialmente de China, Pakistán e India- son, en relación a los otros grupos, las que mayor número de registros presentan anualmente, seguidas de quienes provienen de Sudamérica -Ecuador, Perú y Bolivia- y en tercer lugar quienes arriban de África-Marruecos y Senegal-.

\section{Los barrios de La Salut y Sant Joan de Llefià}

Al igual que en el resto del municipio, en un período de tiempo reducido - 3 añosel número de personas inmigrantes que llegan anualmente se multiplica considerablemente. Sobre los datos del padrón del 2006, encontramos que del total de población de La Salut -20.935 habitantes- cerca del 32\% son personas inmigrantes. Mientras que en Sant Joan de Llefià -con un total de población de 12.785- la proporción es de un $15 \%$.

En ambos barrios, encontramos que las personas provenientes de Asia son en su mayoría de China y Pakistán. Entre los americanos, predominan las personas de origen 
Tabla $\mathbf{N}^{\circ}$ 2. Población según origen por barrio

Habitantes registrados en el padrón al 2006 según origen.

\begin{tabular}{lccc} 
& Sant Joan de Llefià & La Salut & Badalona \\
\hline Españoles & 10.794 & 14.344 & 192.175 \\
Extranjeros & 1.991 & 6.591 & 25.661 \\
\hline Totales & $\mathbf{1 2 . 7 8 5}$ & $\mathbf{2 0 . 9 3 5}$ & $\mathbf{2 1 7 . 8 3 6}$
\end{tabular}

ecuatoriano y boliviano. De África, la mayor proporción provienen de Marruecos, mientras que de Europa oriental destaca quienes vienen de Rumania.

Tabla $N^{0}$ 3. Población por país de nacimiento y barrio

Países con mayor presencia por zona del mundo.

Habitantes registrados en el padrón al 2006.

\begin{tabular}{llcr}
\multicolumn{1}{c}{ Zona del Mundo } & \multicolumn{1}{c}{ País } & Sant Joan de Llefià & La Salut \\
\hline \multirow{2}{*}{ Asia } & China & 266 & 1423 \\
& Pakistán & 182 & 1080 \\
\hline \multirow{2}{*}{ Sudamérica } & Ecuador & 256 & 702 \\
& Bolivia & 61 & 296 \\
\hline Norte de África & Marruecos & 492 & 1242 \\
\hline Europa Oriental & Rumania & 66 & 226 \\
\hline
\end{tabular}

\section{Contexto político: la gestión local de la inmigración}

El hecho migratorio plantea nuevos desafíos e interrogantes para las administraciones locales. Sus iniciativas orientadas a la población inmigrante de origen extranjero se encuentran enmarcadas en las políticas destinadas a la gestión de dicho fenómeno de nivel supramunicipal. La política de extranjería es competencia exclusiva del Estado español, el cual centra su accionar en el otorgamiento de permisos de residencia y control de fronteras. En este sentido la capacidad de incidencia en materia de inmigración por parte de la administración local es reducida (Solà-Morales, 2006).

Dentro de los gobiernos locales la gestión más relevante destinada a los permisos de residencia es la relativa al padrón de habitantes. Este es indispensable para acceder a determinados servicios y como primer paso, aunque no determinante, para conseguir la normalización administrativa de la residencia de las personas inmigrantes. No obstante, las competencias en la gestión de la administración local crecen con la aprobación del 
Estatuto de Autonomía de Cataluña. Por medio de éste, la Generalitat tiene competencias exclusivas en acciones de acogida de las personas inmigrantes, así como en los trámites y gestión inicial de permisos de residencia por trabajo.

El Pla de Ciutadania i Immigració 2005-2008, de la Secretaria per a la Immigració, define las líneas prioritarias por las que se regirán las actuaciones en los distintos ámbitos de la Generalitat, mediante la creación de programas orientados a atender la gestión de la inmigración, gestionar la diversidad y sensibilizar al conjunto de la población. Para el desarrollo de estas acciones en el ámbito local, el Plan cuenta con dos instrumentos: el Programa Integral d'Acollida y los planes territoriales de ciudadanía e inmigración. El primero busca definir un modelo integral para la intervención a nivel autonómico, mientras que los planes territoriales son las herramientas por las cuales se aplica a nivel local la política de la Secretaría.

En el ámbito de la provincia de Barcelona, la Diputación cuenta con el Servei de Polítiques de Diversitat i Ciutadania destinado a dar apoyo a los ayuntamientos en la elaboración de diagnósticos locales, asesoramiento jurídico y formación. En segundo término, esta misma área cuenta con programas específicos -a los cuales pueden acogerse los ayuntamientos- destinados a: recepción y acogida, gestión de la convivencia así como también planes de ayudas a la ciudadanía. Por último, cuenta con servicios destinados a la divulgación, investigación y documentación para dar apoyo técnico a las iniciativas locales.

La realidad que enfrentan los municipios en materia de inmigración y convivencia es heterogénea y requiere de estrategias específicas que sean diseñadas desde estas jurisdicciones. Puntualmente en lo referente a inmigración, conforme ha ido evolucionando el proceso político sobre la materia, los municipios han abandonado un modelo asistencialista para adoptar una visión más integral y orientada a la gestión de la convivencia en el territorio. En este sentido, los ayuntamientos, con diversos matices y dificultades, asumen la gestión del hecho migratorio y diseñan e implementan políticas propias de gestión de la diversidad en el ámbito local, dentro del margen de acción delimitado por las políticas estatales, autonómicas y provinciales.

Mediante la creación de la Regidoria de Drets Civils i Convivència, el ayuntamiento de Badalona crea un instrumento institucional para abordar la gestión de la diversidad en el municipio. Surge de la necesidad de implementar un trabajo a nivel del municipio orientado a la gestión de la convivencia mediante la cohesión social de los ciudadanos, favoreciendo la integración de la población inmigrante en términos laborales y culturales. La intención es trabajar por la convivencia y la integración de una manera transversal, con el conjunto de la sociedad civil, las organizaciones del tercer sector y las distintas dependencias del ayuntamiento presentes en cada barrio. El objetivo es mejorar las condiciones de vida no sólo de los inmigrantes, sino de toda la ciudadanía.

En líneas generales este marco político ha sido propicio para promover un GRAMÀTICAS DE LA CONVIVENCIA. ESTUDIO SOBRE LA CONVIVENCIA EN LA SALUT Y SAINT JOAN 138 DE LLEIFIA, BADALONA 
contexto favorable a la inserción de la población inmigrantes. Ahora bien, en términos de discursos, estos planes hacen referencia a conceptos que tienen un carácter polisémico. En este sentido, la definición política de los mismos no implica necesariamente una implementación en el sentido en el que fueron redactados. La interpretación de los múltiples actores sobre los mismos, se traduce en acciones que aparecen como desfasadas respecto al sentido inicial. Los discursos producidos y reproducidos en la vida social de los actores de los barrios -vecinos, vecinas, representantes de entidades sociales, técnicos de la administración, etc.- les otorgan su propio sentido. Analizar el sentido otorgado por los actores a estos conceptos ha sido clave para enfocar las acciones que se propongan.

\section{Perspectiva teórica}

El análisis ha centrado la atención en los discursos de los actores sociales, buscando dar cuenta de su complejidad y dinamismo. Partimos de una concepción compleja de la realidad social ya que la concebimos como el resultado del conjunto de discursos sociales disponibles, sus confrontaciones y transformaciones. Estos discursos no son exclusivos de una persona o grupo, sino que se entremezclan y los encontramos simultáneamente en los distintos actores. Una misma persona puede sostener distintos discursos, aun siendo éstos contradictorios mientras que un mismo discurso puede ser sostenido por personas muy distintas. Por otra parte, no permanecen inmutables ni estáticos. Se transforman según el contexto en el que se desarrollan, a quién están dirigidos y quién es el emisor del mensaje.

Se trata de elementos dinámicos que se construyen en la interacción con los otros. Son discursos sociales en el sentido que son compartidos, construidos y reformulados constantemente a partir de la interacción de los actores sociales. Para facilitar el análisis, distinguimos tres niveles de producción de estos discursos: macro social, donde incluimos los discursos del Estado, organismos internacionales -política europea puntualmente-, de los medios de comunicación de masas, de los partidos políticos, paradigmas hegemónicos del ámbito académico, así como las diversas instituciones del estado y la administración. El nivel meso social es el espacio de producción de discursos propios de las instituciones del barrio, como de las asociaciones de vecinos, organizaciones comunitarias, colectivos inmigrantes, centros de culto religiosos e instituciones de la administración presentes en el ámbito local. En este último caso, incluimos los discursos que orientan el accionar de las mismas en el espacio local, dejando en el nivel macro social los lineamientos generales marcados por las políticas municipales, provinciales, autonómicas y estatales. ${ }^{4}$ Por último, el nivel micro social

\footnotetext{
${ }^{4}$ Cada nivel de la administración cumple funciones específicas de acuerdo a su ámbito de actuación. En este sentido, los discursos que definen la actuación a nivel macro refiere a las políticas estatales, autonómicas y provinciales de educación, salud, seguridad, etc. Para su aplicación a nivel del barrio, los mismos definirán una serie de funciones específicas de actuación en el espacio local.
} 
refiere al conjunto de discursos individuales o grupales, resultado de la historia personal, familiar y cultural de cada sujeto o colectivo, que entran en juego al momento de establecer relación con los demás.

En el espacio local del barrio, donde centramos este estudio, estos tres niveles discursivos aparecen interrelacionados. La distinción analítica nos permite identificar cómo entran en juego los distintos niveles discursivos, y analizar el marco de relaciones que da origen a distintos tipos de convivencia entre los vecinos. El barrio, definido como el entramado discursivo de los tres niveles de producción de lo social, es el ámbito privilegiado para el análisis de la convivencia. En tanto espacio de relación, encontraremos la interrelación y confrontación de los discursos macro sociales -ley de extranjería, consignas partidarias y mensajes de medios de comunicación-, mesosociales -consignas de asociaciones de vecinos, organizaciones comunitarias, de inmigrantes, religiosas y grupos de interés ${ }^{5}$ - y micro sociales -vivencias, opiniones, cultura e historia de los vecinos-. La identificación de estos elementos en el barrio nos ha permitido definir los límites y posibilidades de acción de las instituciones locales en la gestión de la convivencia, así como el papel que puede desempeñar la relación entre los vecinos en la construcción de la misma.

El análisis centra la atención puntualmente en dos de estos niveles presentes en el barrio: por una parte en los procesos microsociales, donde se despliegan las vivencias, formas de ver y sentir la convivencia por parte de los vecinos. Por otra, los procesos meso sociales, en los cuales analizamos los discursos de las instituciones de la administración y las organizaciones comunitarias respecto a las dinámicas del barrio.

En el territorio, ambos niveles están íntimamente vinculados: las organizaciones comunitarias se han originado a partir del proceso participativo de los vecinos, o son transitadas cotidianamente por ellos. Las instituciones de la administración, si bien en última instancia están definidas por políticas macro sociales, producen un discurso que se diferencia de éstas como fruto de la interacción cotidiana con la comunidad otorgándole un sentido específico a estas políticas. Desde nuestra perspectiva, el entramado institucional es un espacio estratégico para la gestión local de la convivencia. Las instituciones como mediadoras entre lo micro y lo macro, nos permiten un margen de acción importante para trabajar la convivencia en el contexto social actual. Sin realizar un análisis exhaustivo del nivel macro social, nos referiremos a éste en tanto que su relación con los procesos micro y meso sociales -de contraposición, similitud o complementariedad- influye en la definición y transformación de los mismos.

\footnotetext{
5 Agrupaciones que centran su accionar en la defensa de intereses de un grupo definido, como por ejemplo de comerciantes.
}

GRAMÀTICAS DE LA CONVIVENCIA. ESTUDIO SOBRE LA CONVIVENCIA EN LA SALUT Y SAINT JOAN 140

DE LLEFIA, BADALONA

VICTORIA SÀNCHEZ ANTELO; MÒNICA PLANA; FÀTIMA TALEB; ISIDRE FERRETÈ; HASSAN

HAMMICH; MUNIBA MUNIR; JOSEP PALAU; ANTONIO DE LA ROSA; PILAR LAPORTA Y MÒNICA 


\section{Inserción y formas de la convivencia}

La llegada al espacio local de nuevos vecinos, con sus formas de ser, hacer y ver, transforma el entramado de relaciones. El fenómeno de la inmigración ha generado un movimiento discursivo en todos los niveles sociales: sobre cómo definirlo, cómo gestionarlo, sobre la redefinición del papel que debe desempeñar cada actor social y sobre los sentimientos que despierta dicho fenómeno. En este sentido, para el análisis de las relaciones que se establecen entre los diversos niveles discursivos en el barrio, nos interesa señalar algunos procesos que definirán la producción de estos nuevos discursos.

Un primer proceso se refiere a la inserción urbana de la población proveniente de otros países en el barrio, entendida como “... el proceso de paulatina incorporación de los inmigrantes a la ciudad como vecinos, trabajadores, consumidores y usuarios de los servicios públicos." (Torres, 2006: 3) La inserción así entendida, implicará unas formas de uso, tránsito y participación en el espacio público común que marcará las relaciones entre los distintos grupos, otorgando un marco específico que tendrá incidencia en las formas que asuma la convivencia en el barrio. Desde la perspectiva de la sociología urbana, la forma que tome el proceso de inserción en el territorio de la población inmigrante es un factor a tener en cuenta a la hora de analizar los discursos sobre la inmigración, puntualmente por parte de la población autóctona.

En el caso concreto de nuestro ámbito, donde al igual que en otros barrios de centralidad inmigrante, se observa una clara distribución desigual de la población inmigrante respecto a otros barrios del municipio se tornan más visibles los procesos preexistentes de degradación, postergación, falta de recursos y deficiencia de los servicios para la población del barrio (González-Enríquez et al, 2005: 16-24). Este agravamiento de la situación del barrio, afectará la percepción de la población autóctona respecto a la población de otros orígenes, afectando a su vez la convivencia.

Por otra parte, la inserción urbana de la población proveniente de otros países, asumirá distintas características según los discursos macro sociales tiendan a facilitar u obstaculizar esta inserción. En este sentido, las políticas nacionales o autonómicas de gestión de la convivencia entran en relación con los discursos de medios de comunicación y consignas partidarias, generando una producción discursiva que transforma las percepciones de la comunidad sobre el fenómeno. A su vez, la propia historia del barrio y sus habitantes, así como las historias personales vinculadas a la anterior migración y la impronta cultural del país de origen, habilitarán distintos discursos analíticos de la situación. Siguiendo el planteo de Torres (2006), el tipo de inserción urbana de la población será la base que defina las formas que adopte la convivencia en el barrio.

El segundo concepto que debemos introducir por tanto es el de convivencia. En las investigaciones sobre el "fenómeno de la inmigración" surge como necesario 
referirse al concepto de convivencia. La mayoría de los estudios sobre esta temática plantean la necesidad de analizar la convivencia inmigrante-autóctono. Surgen como "novedad" los problemas de convivencia, motivando un sinnúmero de intenciones programáticas por parte de la administración, interpretaciones sobre cómo se desarrolla la vida entre los dos grandes grupos de población -autóctonos e inmigrantes- y sentencias sobre cómo debe ser o hacerse. Desde nuestra perspectiva, la convivencia es una dinámica que se desarrolla en el tiempo -antes, después y más allá del fenómeno migratorio-, que se alimenta del contexto socio-histórico en el que se desarrolla y va transformándose con el devenir del mismo.

Algunos autores como Giménez (2005: 13-15) adjudican al concepto un sentido inherentemente positivo, ya que implica "relaciones e interacciones positivas entre vecinos autóctonos e inmigrantes". Realizando una distinción tipológica de las situaciones sociales, este autor, señala escenarios positivos definidos por la convivencia, frente a situaciones sociales de no-convivencia: definidas por la coexistencia o por la hostilidad. Por su parte, Torres propone darle al término convivencia un sentido desprovisto de valoración, entendiéndola como "el hecho de vivir juntos", como una “... situación que deriva de una inserción residencial de los inmigrantes compartida con los vecinos autóctonos." (Torres, 2006: 2). En este sentido, la convivencia se limitaría a la coexistencia en el espacio. A partir de ésta definición, el autor señala que la convivencia puede adoptar formas distintas: pacíficas, tensas, distantes y/o cercanas. Por último, encontramos analistas que centran la definición en el aspecto relacional y contextual. En referencia a esto, encontramos autores que definen convivencia "com un conjunt d'interrelacions humanes i de tots aquells factors que les condicionen" (Martí, Toribio y Giménez, 2006: 57)

En el estudio definiremos a la convivencia como el resultado de los tipos de inserción urbana que asumen los actores, de las formas de sociabilidad que despliegan en el territorio, que lleva a la interrelación con los discursos sociales disponibles. En este sentido, nos diferenciamos de Giménez, ya que la convivencia no implica en sí una relación positiva. Respecto a Torres, creemos que el hecho de "vivir juntos" implica necesariamente una relación con el otro, pero también con los distintos discursos sociales disponibles -macro, meso o micro discursos-. En este sentido, nos acercamos más a la definición de Martí, definiendo la convivencia como un espacio de relación que excede a lo "humano" e individual, ya que contempla la interrelación de los discursos macro y meso sociales.

El concepto de convivencia así entendido supone una visión dinámica y compleja del entramado de relaciones sociales que dan forma al barrio. Dinámico, en tanto que la interacción de los distintos actores sociales -sujetos particulares, grupos o institucionesdefinirá un tipo de sociabilidad ${ }^{6}$ que dotará de especificidad a la trama organizativa de

\footnotetext{
${ }^{6}{ }^{6}$ Conjunto de relaciones prácticas y agrupamientos sociales que se dan y desarrollan ente el núcleo próximo y los ámbitos del Estado y del Mercado, muy formalizados y con lógicas propias. En este sentido refiere a prácticas y relaciones sociales que, a menudo, se encuentran inscritas en las formas de vivir cotidianamente y que conforman grupos o redes sociales. (Torres, 2006)
} 
la comunidad (Cucó, 2004: 126), definiendo las formas de convivencia. La complejidad del término, estará dada por la interrelación conflictiva de los diversos niveles discursivos, lo cual produce que en un mismo espacio territorial se ensayen distintos tipos de convivencia. Las formas que asuma la sociabilidad de los grupos, en la coexistencia en el barrio, definirán el tipo de convivencia que establezcan entre ellos.

El análisis de la convivencia, las formas en que es definida y condicionarla por los distintos discursos, reviste especial interés si se asumen que escenarios de conflicto. Su extensión en el tiempo pueden originar procesos de guetificación (Wacquant, 2001), basados en la escisión, tanto relacional, espacial como institucional, entre los distintos colectivos y particularmente respecto a la población autóctona y sus instituciones.

Otros discursos destacan positivamente los escenarios basados en la tolerancia. En estos escenarios, donde en principio no se observa explícitamente conflicto, la copresencia en el espacio público se sustenta en las relaciones entre los grupos que asumen una actitud de adaptación y tolerancia al otro, no implican un intercambio entre los mismos. La resolución de los conflictos se limita a "una voluntad común de evitar las situaciones conflictivas, de compartir sin tropiezos los espacios comunes." (Germain et. al., 1995: 296). Este escenario sería el propio de modelos multiculturales, en el sentido que vecinos de diversos orígenes comparten los espacios públicos, pero las relaciones superficiales, basadas en la reserva y el principio de "no interferencia" se constituyen como una estrategia colectiva que permite la coexistencia sobre la base de la tolerancia (Toubon, 1990). Este tipo de estrategia, en una primera etapa puede favorecer la inserción de los vecinos inmigrantes en el barrio, no así su integración como parte de un todo. En este modelo se asume que tanto inmigrantes como autóctonos identifiquen códigos y normas implícitas que faciliten ésta "no interferencia" entre los vecinos. Cabe destacar, que si bien las relaciones basadas en la tolerancia pueden ser un primer paso, que facilite la inserción, supone un equilibrio inestable ya que el conflicto está siempre latente: en cuanto no se comprende el código se quiebra la "no-interferencia".

La identificación de los distintos escenarios de convivencia presentes en los barrios nos ha permitido conocer las voces de los protagonistas, acceder a los distintos discursos disponibles para la definición de las relaciones entre vecinos, analizar la viabilidad de las propuestas para la gestión de la convivencia y consolidar la base de apoyo a las políticas marco de dicha gestión. Para alcanzar este objetivo, el estudio se ha desarrollado con un equipo de investigación compuesto por personas de distintos orígenes: Marruecos, Ecuador, Argentina, Pakistán, China y Catalunya. Sin ser determinante, esto ha permitido un acercamiento a los distintos colectivos con el fin de recoger las formas de ver, hacer y sentir la vida cotidiana en estos barrios. 


\section{Discursos sobre la convivencia}

Entre los escenarios de convivencia presentes en los barrios encontramos situaciones bastante polares. Por una parte, priman las tensiones, el rechazo, el autoritarismo; mientras que en el polo opuesto, destaca una necesidad imperiosa construir relaciones de acercamiento. Se observan situaciones intermedias, de relaciones de menos implicación, más superficiales y por tanto de menos conflicto.

\section{Los vecinos como amenaza: convivencia tensa y reconocimiento negativo}

Los discursos que definen a este tipo de convivencia son aquellos que ubican a los inmigrantes como responsables de los principales problemas del barrio. Para muchos vecinos, tanto autóctonos como inmigrantes, la presencia de personas provenientes de otros países ha generado el deterioro del barrio. Esta degradación, señalan, se identifica en la higiene de los espacios públicos, la falta de servicios y las condiciones de las viviendas. Este sentimiento de amenaza, se visualiza al señalar que la llegada de nuevos vecinos al barrio produce un quiebre en la comunidad, en sentido de relaciones de confianza y cercanía que caracterizaban al barrio. Definen su cotidiano en el barrio como marcado por un gran temor a transitar los espacios público, debido a la presencia de inmigrantes en todos los espacios.

Entre algunos vecinos españoles que han vivido un proceso migratorio, más que identificarse con la experiencia de aquellos que hoy cambian de hogar, se marcan diferencias que buscan reafirmar la distancia entre ellos y los inmigrantes actuales. Entre los autóctonos, estos sentimientos de temor y gran desconfianza que generan las personas inmigrantes, se sostienen mediante la deshumanización de la persona proveniente de otros países. La estigmatización se construyen entremezclando experiencias vividas, mensajes sostenidos por partidos políticos de derecha y medios de comunicación. Esta interrelación discursiva permite generalizar un hecho particular a todo el colectivo inmigrante.

Este reconocimiento negativo del otro, suele vincularse a contextos de inseguridad, devaluación de la calidad de vida del barrio, reducción de la clientela de "toda la vida" en los comercios, cierre de los establecimientos propiedad de autóctonos, pérdida del valor inmobiliario. En resumen, situaciones de malestar que se agrava por el sentimiento de abandono por parte de la administración. La valoración negativa del vecino de otro origen, promueve así una relación de distancia, que no hace más que ampliar la distancia respecto a los nuevos vecinos, profundizar el desconocimiento y agravar los sentimientos de temor y rechazo.

Por otra parte, entre algunos inmigrantes se observa una reproducción del discurso del rechazo sostenido por los autóctonos. En este caso, se utiliza para diferenciarse de aquellos que son definidos como "no aceptables" en la sociedad de acogida. Estos 
discursos cercenan la posibilidad de acercamiento. Facilitan el establecimiento de relaciones violentas, sean estas por enfrentamiento físico o discursivo. Las manifestaciones desarrolladas en el barrio contra los rumanos gitanos son una muestra de ello. En este sentido, las estrategias de resolución de conflictos propuestas por estos discursos se sintetizan en el siguiente fragmento:

"Llamarle la atención dos o tres veces y enseñarles que hay una autoridad. Que aquí en España hay una autoridad. Que aquí ellos no vienen a ser dueños de España. Que aquí hay una autoridad y que aquí viven personas. Y eso es todo, mire lo siento" (Mujer, extremeña).

En este escenario de convivencia, la relación con el vecino se define por establecer asimetrías. De un lado quienes son dueños y del otro los que están "de prestado". Esta percepción sobre el lugar que debe ubicar el vecino inmigrante en esta sociedad producirá, sin lugar a dudas, algunas resistencias. Estas son las principales fuentes del conflicto. El espacio público es actualmente el lugar en el que se visualizan estos enfrentamientos. La intervención de la policía en algunos parques es síntoma de esto. Sin embargo, la exclusión de los inmigrantes no resuelve el conflicto.

Estas actitudes de rechazo, promueven que el menor incidente, por insignificante que parezca, desate un enfrentamiento. Incluso, algunos malos entendidos o malas interpretaciones se definen como provocación y desatan la ira. Los discursos del distanciamiento y rechazo, llevan al establecimiento de grupos cerrados sobre si mismos, punto de partida para procesos de guetificación del barrio. El gueto como horizonte no aparece valorado por ningún vecino. Sin embargo, estos discursos tienden a construir las murallas de los guetos.

\section{Adaptación y tolerancia: convivencia pacifica, pero distante}

Esta forma de convivencia es la menos extendida entre los vecinos. El discurso de la adaptación es utilizado por algunos autóctonos, pero principalmente por los inmigrantes que buscan diferenciarse de aquellos que no son "deseados" en la sociedad de acogida. Se sostiene una valoración positiva de los vecinos de otros orígenes por que "no se ven", "no se oyen" y que parecen uno más. Entre algunos vecinos autóctonos se menciona como un deseo ya que se asume la presencia de inmigrantes como algo que no tiene vuelta atrás. En este sentido, se espera que aprendan a vivir cívicamente, que se adapten a las costumbres, y a cambio se ofrece una actitud tolerante frente a la presencia del otro.

Entre algunos inmigrantes, la adaptación es un objetivo para facilitar su inserción en el barrio. Implica adoptar costumbres y formas acordes a la realidad del nuevo barrio. Está búsqueda de adaptación, se utiliza en respuesta a los autóctonos frente a los discursos que generalizan aspectos negativos de algunos hacia todo el colectivo inmigrante.

Este binomio adaptación/tolerancia se sostiene en una relación superficial, que no 
pasa de cumplir con los ritos de saludarse en la escalera o en los espacios públicos. Las estrategias de resolución de conflictos se acercan a un contacto, en el cual unos les enseñan a los otros cómo deben comportarse, y el éxito de esta gestión se basa en que los últimos accedan a modificar sus prácticas. En este sentido, como estrategia de convivencia, permite un escenario pacifico, multicultural, en el sentido de coexistencia de vecinos de distintos orígenes. Como primer paso, posterior a las situaciones de conflicto es una posibilidad. Sin embargo, a largo plazo se convierte en un escenario difícil de sostener. Siendo barrios postergados, donde la escasez de recursos es el signo distintivo, el conflicto se mantendrá latente. La convivencia se tornará fácilmente conflictiva cuando la coexistencia implique disputar recursos escasos. En este sentido, el vecino inmigrante se convierte en una amenaza.

La convivencia pacifica, pero basada en la distancia, no permite resolver los problemas de base: la escasez de recursos, el desconocimiento del otro y el temor que esto pueda acarrear a la larga genera conflictos de convivencia. Ante situaciones en las cuales las "buenas maneras" no basten, ya que desconocemos qué entiende el otro por "buenas maneras", el conflicto estará nuevamente marcando la pauta de relación. Este tipo de convivencia, supone entonces el reconocimiento de un código común, sobre el cual todos nos esforzamos por respetar y no interferir en el cotidiano del otro. Como vimos en el análisis no es el caso de los barrios. La coexistencia de los discursos más conflictivos, hace difícil sostener aquellos que apuntan a una actitud tolerante.

\section{Historias comunes: convivencia basada en el acercamiento e intercambio}

“... aquí no hay rechazo, hay malos entendidos” (Varón, pakistaní)

Por último, encontramos los discursos que proponen una mirada crítica sobre las fuentes del conflicto. Éstos sostienen que las problemáticas de estos barrios se originan en distribución desigual y la falta de recursos del municipio. Esta característica es una constante en la historia de La Salut y de Sant Joan de Llefià. Los vecinos autóctonos señalan que en los años 60 y 70 se vivieron situaciones iguales o incluso peores que la actual. Esto motivó la participación activa de los vecinos y posibilitó la obtención de mejoras para los barrios.

Los vecinos que han pasado por la experiencia migratoria de entonces, destacan que los problemas de vivienda obligaban a hogares sobrepoblados. Señalan que la estrategia de inserción se basaba en vivir cerca de sus paisanos, ya que permitía acceder a una red de contención para los recién llegados. En este sentido, no encuentran grandes diferencias con respecto a los nuevos inmigrantes. Recuerdan que la experiencia de rechazo también la compartieron. Esto lleva a proponer el establecimiento de relaciones basadas en el intercambio y el reconocimiento de los nuevos vecinos.

Entre los inmigrantes, se observa que darse a conocer, buscar las relaciones de proximidad y romper con la desconfianza se vuelven una respuesta necesaria a los 
rechazos de los vecinos, sean autóctonos o de otros grupos de inmigrantes. Este grupo de discursos propone cuestionar los mensajes de los medios de comunicación que muestran a los inmigrantes como ladrones o amenazantes, al tiempo que proponen definir a todos como vecinos que forman parte del barrio.

Las estrategias de resolución de conflictos apuntan al diálogo, reconociendo que muchos problemas de la convivencia son los que se pueden tener con cualquier vecino, sin que la procedencia se convierta en el factor que los origina. Por otra parte, identifican que muchos de los conflictos se deben a malas interpretaciones de las acciones del otro, por tanto conocerlo es una forma de reducir los conflictos.

Estos vecinos desarrollan acciones que buscan el encuentro desde la diversidad, sobre la base de que el vecino, sea autóctono o inmigrante, tiene algo que aportar, algo que vale la pena conocer. Este proceso de descubrimiento de nuestros vecinos, requiere esfuerzos, tiempo y una actitud que evite prejuzgar y simplificar las acciones de los otros. Las experiencias recogidas entre los vecinos que han construidos puentes, resaltan por su sencillez, ya que responden a pequeñas acciones cotidianas que facilitan perder el miedo respecto a los otros.

\section{Las instituciones y su papel en la definición de la convivencia}

La existencia de los discursos de rechazo requiere de espacios que potencien estas últimas experiencias de acercamiento. En este sentido, las instituciones del barrio son los espacios que pueden fijar las bases para una buena convivencia. En las asociaciones de vecinos encontramos que su pasado reivindicativo puede definirlas como el canal privilegiado para la gestión de los conflictos favoreciendo el acercamiento y reconocimiento a través de acciones de mediación e intercambio. Sin embargo, el descrédito de las mismas por parte de muchos vecinos es un obstáculo que se debe superar. Al tiempo que, muchas de las asociaciones reproducen los discursos del rechazo, por tanto no reconocen a los inmigrantes como vecinos.

Otros espacios posibles de participación que pueden orientar la gestión de la convivencia son las organizaciones comunitarias. Estas cuentan con una relación más próxima con distintos grupos de la comunidad, algunas con una mirada más profesional sobre cómo trabajar los temas comunitarios y una concepción que reconoce la diversidad como un valor fundamental de las relaciones entre los vecinos. Sin embargo, en la mayoría de los casos, pierden la mirada de conjunto, dificultando la coordinación y complementariedad de las acciones que permitiría superar la fragmentación del sector.

Entre las organizaciones gestionadas por inmigrantes encontramos que existen intentos por trabajar en espacios de encuentro, con una variedad de propuestas que 
invitan a la participación. Sin embargo, ninguna logra desprenderse el rótulo de "organización para inmigrantes". Esto dificulta la concreción de las propuestas de diálogo con la comunidad autóctona. La definición de convivencia que hacen aún no es compartida por algunos vecinos, por tanto las acciones de sensibilización serán un requisito previo para consolidarse como espacios de gestión de una convivencia que apunte a la integración basada en el reconocimiento, la igualdad de derechos y responsabilidades.

\section{Notas finales}

Nos parece importante señalar que para desmontar los discursos de rechazo, tanto de vecinos como de partidos políticos y medios de comunicación, es preciso definir un nosotros inclusivo. Es decir, desde el momento en que elegimos vivir en este barrio nos convertimos en vecinos, seamos o no inmigrantes, y esto nos obliga a contribuir a mejorar la convivencia. Pero esa inclusión no puede ser en términos de adaptación de unos y actitudes de tolerancia de otros. Debe ser de intercambio y reconocimiento de ambas partes. De igualdad de oportunidades en igualdad de condiciones en los procesos de toma decisión. En una primera etapa a nivel de organizaciones del barrio, como parte del "Nosotros, los vecinos de La Salut y de Llefià". Esta redefinición del nosotros, es la base para la reivindicación de mejoras del barrio. Pero ese nosotros implica pactar qué barrio queremos, cómo lo queremos y de qué parte nos debemos hacer cargo para conseguirlo.

En una segunda instancia, este nosotros nos puede permitir definirnos como ciudadanos con igualdad de derechos y responsabilidades. Pero para eso hay mucho camino que recorrer. La definición de propuestas para alcanzar un escenario de convivencia determinado, requiere que definamos qué convivencia queremos. Las acciones necesarias para lograrlo, deben ser pactadas, negociadas y compartidas. 


\section{Bibliografía}

Ajuntament de Badalona (2005), Pla de Convivencia en la Diversitat.

Bialakowsky, A. et al. (2004), "Procesos sociales de exclusión-extinción. Comprender y coproducir en las prácticas institucionales en Núcleos Urbanos Segregados”, en Mota Díaz, L. y Cattani, A. D. (Coords.), Desigualdad, pobreza, exclusión y vulnerabilidad en América Latina. Nuevas perspectivas en América Latina, coedición de la Facultad de Ciencias Políticas y Administración Pública, Universidad Autónoma del Estado de México (UNAM) y Centro de Estudios sobre Marginación y Pobreza del Estado de México (CEMAPEM), Universidade Federal do Rio Grande do Sul, Asociación Latinoamericana de Sociología (ALAS), Toluca, México, 2004, páginas 101-142.

Cucó, J. (2004), Antropología Urbana, Ariel, Barcelona.

De Marinis, P. (2005), 16 comentarios sobre la(s) sociología(s) y la (s) comunidad(es), Papeles del CEIC $\mathrm{N}^{\circ}$ 15, Universidad del País Vasco. f" http://www.ehu.es/papeles/15.pdf [obtenido el 09/02/2007].

Fundació Jaume Bofill (2003), "Participació i immigració en contextos pluriculturals. La situció del Casc Antic de Barcelona”, Finestra Oberta $\mathrm{N}^{\circ} 33$.

Fundació Jaume Bofill (2004), “La Immigració a Debat: Diversitat i Participació”, Debats No 4, Barcelona.

Garcés, A. (2006) "Configuraciones espaciales de lo inmigrante: usos y apropiaciones de la ciudad", Papeles del CEIC $\mathrm{N}^{\circ}$ 20, http://www.ehu.es/papeles/20.pdf [obtenido el 09/02/2007]

Germain, A. (coord.); Archambault, J.; Blanc, B., Chambnneau, J.Dansereau, F. y Damaris, R. (1995), "Cohabitation interethnique et vie de quartier", Collection Éstudes et Recherches, Misnistere des Affaires internatcionals, de l'Immigration et des Communautés culturelles du Québec, Montréal.

Giménez, C. (2005), “Convivencia: conceptualización y sugerencias para la praxis”, Puntos de Vista $\mathrm{N}^{\circ} 1$, pp.7-31.

González Enríquez, C. y Álvarez-Miranda, B. (2005), Inmigrantes en el barrio. Un estudio cualitativo de opinión pública, Ministerio de Trabajo y Asuntos Sociales, Madrid.

Ibañez, J. (1991), El regreso del sujeto. La investigación social de segundo orden, Amerindia, Santiago de Chile.

Martí, P.; Toribio, L. y Giménez, C. (2006), "El barri, espai de convivència”, Quaderns de Carrer, No 1. Barcelona, pp. 29-84.

Martínez Aranda, M. A (2006), "Relaciones vecinales e inmigración en Madrid", Colección de monografías, $\mathrm{N}^{\circ}$ 2, serie Naranja: Estudios antropológicos. Observatorio de las Migraciones y de la convivencia intercultural de la Ciudad de Madrid, Madrid.

Monnet, N. (2000), "El uso del espacio público por parte de los nuevos habitantes del casc antic de Barcelona: continuidad e innovaciones", Scripta Nova, Revista Electrónica de Geografía y Ciencias Sociales, Universidad de Barcelona, Barcelona.

Requena Hidalgo, J. (2003), "La peor casa en el peor barrio. Barrios de inmigración y marginalidad en la periferia urbana de Barcelona. el caso de Badalona”, Scripta Nova, Revista Electrónica de Geografía y Ciencias Sociales, Universidad de Barcelona, Barcelona.

Solà-Morales, R. (2006), "La gestió de la Immigració a l'àmbit local. Reptes i Actuacions” para la Fundació Jaume Bofill. Finestra Oberta, Barcelona.

Torres Pérez, F. (2005), "Los espacios públicos en la ciudad multicultural. Reflexiones sobre dos parques en Valencia". Puntos de Vista, Cuadernos del Observatorio de las Migraciones y de la Convivencia Intercultural de la Ciudad de Madrid, $\mathrm{n}^{\circ}$, Madrid. 
Torres Peréz, F. (2006), "Las dinámicas de la convivencia en un barrio multicultural. El caso de Rassafa (Valencia)", Papeles del CEIC, vol. 2006/1, papel No 23. http://www.ehu.es/papeles/23.pdf [obtenido el 09/02/2007]

Toubon, J. C. y Messamah, K. (1990), Centralié immigreé. Le quartier de la Goutte d'Or, L'HarmattanCIEMI, Paris.

Wacquant, L (2001), Parias Urbanos. Marginalidad en la ciudad a comienzos del milenio, Ed. Manantial, Buenos Aires, p. 204. 